\title{
SUPREMO TRIBUNAL FEDERAL E AS PROPAGANDAS ELEITORAIS
}

\author{
Carlo José Napolitano’
}

\section{Palavras-Chave}

Supremo Tribunal Federal /

políticas públicas de comunicação /

propaganda eleitoral

\section{SUMÁRIO}

\section{Introdução}

\section{Métodos e técnicas utilizados}

\section{na pesquisa empírica}

\section{Apresentação dos julgados}

3.1. ADI 956

3.2. ADI $3741 / 3742 / 3743$

3.3. ADI 3758

3.4. ADI 4741

\section{Considerações sobre}

os julgamentos em sede

de conclusão

5. Referências

\section{Resumo}

Trata-se o presente de relato de pesquisa que considera que, a partir dos anos 90, o Supremo Tribunal Federal passou a exercer um papel de centralidade nas decisões políticas brasileiras, além de executar a função precípua de guardião da Constituição. Algumas dessas decisões do STF, por hipótese, impactam os meios e as atividades da comunicação social, influenciando o exercício da liberdade de expressão, da democracia e da cidadania, bem como estabeleceram critérios que balizam a formulação e implementação de políticas públicas de comunicação. Nesse sentido, a pesquisa visa analisar decisões proferidas pelo STF de 1988 a 2016 que tenham relação com a temática proposta, no intuito de investigar se há um modus operandi do STF nos julgamentos acerca das políticas públicas de comunicaçãoA, relacionados à liberdade de expressão do pensamento. O presente trabalho visa apresentar e debater os achados da pesquisa relativos à temática da propaganda eleitoral, inferindo que não é possível indicar um modus operandi nos julgamentos do STF relativo à liberdade de expressão do pensamento quando relacionada a essa política pública de comunicação. 


\title{
BRAZILIANSUPREMECOURTAND THE ELECTIONS PROPAGANDA
}

\author{
Carlo José Napolitano
}

\section{Keywords}

Brazilian Supreme Court / public policies of communication / elections propaganda

\begin{abstract}
The present essay is a research report that considers that since the 90's the Brazilian Supreme Court began to play a role of centrality in Brazil's political decisions, in addition to performing its essential function of guardian of the Constitution. Some of the STF political decisions hypothetically impact the media and the activities of the media, influencing the exercise of freedom of speech, democracy and citizenship, as well as established criteria that guide the formulation and implementation of public policies on communication. In this context, the proposal aims to investigate decisions made by the Supreme Court in the period 1988-2016 and that relate to the proposed theme, in order to investigate if there is a modus operandi of the Brazilian Supreme Court in the judgments about the public policies of communication related to the freedom of speech. The present study aims to show and discuss the findings of the research related to the topic of the elections propaganda, concluding that it is not possible to indicate a modus operandi in the Brazilian Supreme Court judgments about freedom of speech when related to this public communication policy.
\end{abstract}




\section{Introdução}

Trata-se o presente de estudo empírico, baseado em análise de jurisprudência, acerca de decisões do Supremo Tribunal Federal relacionadas às regulações de propaganda eleitoral.

O texto é um dos resultados de pesquisa e tem como objetivo específico analisar e interpretar decisões do Supremo Tribunal Federal - (STF) relacionadas às políticas públicas de comunicação, em especial, às relacionadas à temática da liberdade de expressão do pensamento.

A pesquisa da qual resulta o presente trabaIho partiu de algumas premissas, dentre as quais, que uma das peculiaridades do atual sistema constitucional brasileiro reside no fato de ele ser repleto de regulações relacionadas a diversos campos da atividade econômica e social. O termo regulação está sendo usado no sentido de regulação normativa que compreende, segundo Aguillar (2006), a regulamentação legal e as atividades acessórias de fiscalização e imposição de sanções para as condutas ilícitas. São, portanto, medidas estatais, tanto legislativas como administrativas, que visam controlar e ou influenciar os comportamentos "dos agentes econômicos, tendo em vista orientá-los em direções desejáveis e evitar efeitos lesivos aos interesses socialmente legítimos" (CARVALHO, 2002, p. 13). Regular, em outras palavras, seria definir direitos e deveres, delimitar o exercício de direitos, clarificar as suas condições de uso, defender a sociedade e o indivíduo contra eventuais maus usos dos direitos (GONÇALVES, 2003). Nesses termos, compreende-se que a regulação jurídica da liberdade de expressão do pensamento pode ser medida através da análise da disciplina, constitucional e legal, produzida pelo Congresso Nacional, que define e delimita direitos, bem como pela interpretação conferida a esse direito fundamental pelo Supremo Tribunal Federal que, no limite, é o órgão responsável por clarificar as condições de uso de direitos previamente estabelecidos.

Considera ainda que a Constituição brasileira, de 05 de outubro de 1988, tem caráter substancial, programática, dirigente, tendo em vista que ela estipula inúmeras finalidades, objetivos e valores que o Estado e a sociedade brasileira devem concretizar ou pelo menos almejar; que a comunicação social é um desses campos ou dimensões da vida social regulados constitucionalmente; que diversos valores relacionados à comunicação social foram constitucionalizados; que a despeito da regulação constitucional, sempre será necessária a elaboração de leis que regulamentem os dispositivos constitucionais;' que as normas regulamentadoras da Constituição, muitas vezes, têm caráter de políticas públicas governamentais, algumas delas impactando o exercício da liberdade de expressão do pensamento; que ao STF foi atribuída a tarefa de guardião do texto constitucional e, tendo em vista essa tarefa, o Supremo é constantemente chamado para verificar a compatibilidade das políticas públicas com a ordem constitucional vigente e, por fim, que algumas políticas públicas adotadas através de normas jurídicas e relacionadas à comunicação social e

Como exemplos de possibilidade de regulação podem ser citados os seguintes dispositivos constitucionais: artigo $5^{\circ}$, IV que dispõe ser livre a manifestação do pensamento, vedando-se o anonimato; artigo $5^{\circ}, \vee$ que garante o direito de resposta; artigo $5^{\circ}$, XIV que assegura o acesso à informação, resguardado o sigilo da fonte; artigo $5^{\circ}$, XXXIII que garante o acesso às informações públicas, ressalvadas aquelas imprescindíveis à segurança da sociedade e do Estado; art. 220 , parágrafo $3^{\circ}$ que prevê a edição de lei federal para regular as diversões e espetáculos públicos, no que diz respeito a sua natureza e faixa etária indicada e adequação de local e horário de apresentação (inciso I) e regular a propaganda de produtos, práticas e serviços que possam ser nocivos à saúde e ao meio ambiente (inciso II, segunda parte); art. 220, parágrafo $4^{\circ}$, que prevê a restrição à propaganda comercial de tabaco, bebida alcoólica, agrotóxicos, medicamentos e terapias, dentre outras previsões constitucionais e a regulação da propaganda eleitoral. 
que impactaram a liberdade de expressão do pensamento tiveram e têm a sua constitucionalidade questionada perante o STF, sendo possível, desta forma, extrair algumas conclusões acerca da interpretação do Supremo em relação às políticas públicas relacionada à comunicação social e as suas consequências, em especial, aquelas relacionadas ao direito fundamental de liberdade de expressão do pensamento.

Por hipótese, a pesquisa, da qual resulta este trabalho, considerou que ao decidir casos referentes à temática, o STF sistematicamente amplia a aplicação desses direitos, eliminando qualquer forma ou possibilidade de regulação, potencialmente, impactando as políticas públicas direcionadas ao setor.

Considera-se também que já há uma produção científica considerável acerca da centralidade política do Judiciário, ${ }^{2}$ no entanto, verifica-se uma carência de estudos e análises referentes às decisões do STF, ${ }^{3}$ em especial, aquelas relacionadas às atividades da comunicação social, ${ }^{4}$ ponderando-se, contudo, que há sim algumas pesquisas e artigos que trataram direta ou indiretamente dessas questões (BRITTOS e NAZÁRIO, 2011; NITRINI, 2013; REALE JÚNIOR, 2010; ZYLBERSZTAJN, 2008), no entanto, de forma pouco sistematizada, objetivando a pesquisa preencher essa lacuna.

Desta forma, o projeto de pesquisa tem por objetivo principal e substancial analisar e interpretar decisões do Supremo Tribunal Federal relacionadas às políticas públicas de comunicação, em especial, aquelas direta-

\footnotetext{
2 Destacando-se os seguintes trabalhos nacionais e internacionais: GARAPON (2001); KOERNER e MACIEL (2002): MAUS (2000): SADEK (1995); SHAPIRO, SWEET (2002); TATE, VALLINDER (1994); VIANNA et al (1999); VIEIRA (2002), dentre outros.

3 Há excelentes trabalhos e pesquisas sobre o processo decisório das cortes e do próprio Supremo Tribunal Federal, como são os casos de Mendes (2011; 2013) e Silva (2009; 2013).

4 Algumas pesquisas e artigos trataram direta ou indiretamente dessas questões (BRITTOS e NAZÁRIO, 2011; NITRINI, 2013; REALE JÚNIOR, 2010; ZYLBERSZTAJN, 2008)
}

mente relacionadas à liberdade de expressão do pensamento, no intuito de verificar se há uma linha mestra, ou em outros termos, um modus operandi de interpretação do STF relacionada às políticas públicas de comunicação.

Como objetivos secundários, visa o aprofundamento teórico das seguintes temáticas: liberdade de expressão do pensamento; limitação dos direitos fundamentais; núcleo essencial dos direitos fundamentais; processo decisório (deliberação) do STF, sendo essa última uma questão formal enfrentada pela pesquisa.

Pelo fato de a pesquisa estar intimamente pautada à comunicação social e considerando a aderência e atuação profissional do pesquisador com essa área do conhecimento, esse último aspecto da pesquisa bibliográfica está diretamente relacionada com o que foi denominado de "diálogo externo" do STF com a sociedade civil organizada e, em especial, com os meios de comunicação social. Em outros termos, com a "deliberação externa do STF", que de acordo com Silva (2009, p. 210), trata-se de um esforço de convencimento de "atores externos ao grupo" (SILVA, 2010, p. 43) e que, sobretudo, teria o papel "de chamar a atenção da sociedade civil, ou pelo menos da comunidade acadêmica e jornalística, para questões fundamentais no cenário político-jurídico de um país" (SILVA, 2009, p. 211-212), como foram os casos das decisões proferidas pelo STF em ações relacionadas às políticas públicas de comunicação.

O presente trabalho trata especificamente de decisões do STF proferidas em controle principal e abstrato de constitucionalidade e relacionadas à propaganda eleitoral e está assim estruturado: além desta introdução, a 
próxima seção aborda os métodos e técnicas utilizados na pesquisa empírica, na seção seguinte são apresentados os julgados do Supremo relacionados à temática da propaganda eleitoral e, por fim, apresentam-se algumas considerações em sede de conclusão, especialmente, o entendimento de que não é possível indicar um modus operandi nos julgamentos do STF relativo à liberdade de expressão do pensamento quando relacionada à política pública de comunicação de propaganda eleitoral.

\section{Métodos e técnicas utilizados na pesquisa empírica}

Foram pesquisadas no site do Supremo Tribunal Federal as ações constitucionais ${ }^{5}$ relacionadas com a temática das políticas públicas de comunicação e ligadas à liberdade de expressão do pensamento. O recorte temporal da pesquisa inicialmente previa o período das decisões do Supremo Tribunal Federal de 1988 a 2015, no entanto, decidiu-se ampliar esse período de análise para o ano de 2016, considerando que decisões importantes do STF foram proferidas sobre a temática das políticas públicas de comunicação durante o esse ano e que mereceriam análise na pesquisa, como foi o caso, por exemplo, da ADI 4741, que será aqui analisada.

A pesquisa empírica foi realizada no portal do Supremo Tribunal Federal onde há um sistema de pesquisa de jurisprudência através de palavras-chave http://www.stf.jus.br/ portal/jurisprudencia/pesquisarJurisprudencia.asp.

\footnotetext{
5 No projeto de pesquisa, do qual resulta o presente trabalho, classificou-se inicialmente como ações constitucionais as ações diretas de inconstitucionalidade, ações declaratórias de constitucionalidade, arguições de descumprimento de preceitos fundamentais; recursos extraordinário e reclamações. Optou-se, no entanto, analisar somente as ações relacionadas ao controle principal e abstrato de constitucionalidade, tendo em vista tratarem-se de processos objetivos e que, em tese, demandam apreciações também objetivas da Corte.
}

A pesquisa realizada no site do STF utilizou os termos "liberdade de expressão", "liberdade de imprensa", "políticas de comunicação" e "políticas públicas de comunicação". Os mesmos argumentos foram utilizados em solicitação de pesquisa jurisprudencial à Seção de Pesquisa de Jurisprudência do próprio Supremo. Estas últimas estão disponíveis em http://tinyurl.com/jcgu2x8 e http://tinyurl.com/ho5n3uh. ${ }^{6}$

Com esses termos a pesquisa retornou com 37 referências. Considerando a leitura dos acórdãos e as diversas referências a julgamentos anteriores do próprio STF, como foi o caso da ADI 2815, além de pesquisas anteriores do pesquisador, chegou-se a um total de 66 ações.

Os resultados da pesquisa indicaram diversas ações, no entanto, algumas foram de pronto excluídas, pois não compunham o objeto da pesquisa, como foi o caso da ADI 4638, na qual a expressão "liberdade de expressão" foi encontrada somente na base doutrinária do acórdão. Outras no mesmo sentido tratavam de assuntos diversos e a expressão aparecia em outro sentido, como são os casos das ADIs 3512 e 1950, que apresentaram no texto do acórdão a seguinte frase: "a livre iniciativa é expressão de liberdade".

Com a expressão "liberdade de imprensa" a maioria das ações, 12 no total, localizadas na busca, tanto na efetivada pelo site quanto a solicitada à seção de pesquisa de jurisprudência do STF, não estavam diretamente relacionadas ao conceito, mas sim justificava a extinção do processo por falta de legitimidade ativa de partido que perdeu representação no Congresso, como são os casos das

6 Nessa pesquisa foram localizadas centenas de acórdãos, no entanto, com a expressão "implementação de políticas públicas". A pesquisa jurisprudencial foi realizada nos meses de janeiro e fevereiro de 2017. 
ADIs 1890 e 2060, por exemplo.7

Outras, após a leitura dos acórdãos, indicaram a não pertinência com a temática das políticas públicas de comunicação, muito embora estejam diretamente relacionadas à liberdade de expressão do pensamento, como foram os casos das ADIs 1969 e 4274 que tratavam respectivamente do direito à reunião e da liberdade de manifestação pública para a descriminalização do uso de maconha, o mesmo objeto da ADPF 187, também excluída da base de dados para a análise.

Feitas as exclusões mencionadas, chegouse ao número final de 40 ações.

Para a análise efetiva das ações, outro recorte foi estabelecido. Optou-se por analisar somente as ações que receberam julgamento definitivo do plenário do STF, com ou sem a análise do mérito, em um total de 21, excluindo-se as que receberam apenas julgamento liminar, quatro delas, e aquelas nas quais o relator já proferiu voto, no entanto, o processo ainda não se encerrou, juntamente com as que ainda não foram apreciadas pelos respectivos relatores, estando nessa situação 15 ações, totalizando as 40 que compõe o banco de dados para análise. As ações pendentes, juntamente com outras que certamente serão protocoladas, serão objeto de análises futuras, pois pretende-se continuar com a investigação objeto da presente pesquisa, em uma atividade constan$7 \mathrm{Na}$ pesquisa da Seção de Pesquisa de Jurisprudência, há referência 11 ações com essa justificativa. O termo aparece na seguinte citação, em decisão de relatoria do Min. Celso de Mello "O alto significado po lítico-jurídico dessa participação institucional das agremiações partidárias, no plano do controle normativo abstrato, foi bem destacado no douto magistério expendido por CLÈMERSON MERLIN CLÈVE ("A Fiscalização Abstrata da Constitucionalidade no Direito Brasileiro", p. 171/172, $2^{\mathrm{a}}$ ed., 2000, RT): "Por outro lado, a legitimidade ativa dos partidos vem contribuir para o aprimoramento do Estado Democrático tidos vem contribuir para o aprimoramento do Estado Democratico de Direito, uma vez que forlamento. Há as minorias ali representadas que, devidamente articuladas, formam o bloco de oposição. Cabe a esta, a oposição, propor modelos políticos alternativos e, mais do que isso, provocar a ação fiscalizadora do Parlamento. Sabe-se dos efeitos que essas atuações produzem, mormente no contexto de uma sociedade plura que admite, sem maiores restrições, a liberdade de imprensa. A Constituição de 1988 preocupou-se com o direito de oposição, a começa quando inscreve entre os fundamentos da república o pluralismo político (art. $7^{\circ}$ da CF)." Por esse motivo, todas foram excluídas da análise. te de observatório do Supremo Tribunal Federal relativo às políticas de comunicação. As seguintes ações, portanto, foram excluídas da análise: ADI 2566, ADI 2677, ADI 3987, ADI 4451, ADI 4679, ADI 4923, ADI 4747, ADI 4756, ADI 5275, ADI 5415, ADI 5424, ADI 5432, ADI 5436, ADI 5613, ADO 9, ADO 10, ADO 11, ADPF 246 e ADPF 379.

Diante disso, as 21 ações já analisadas na pesquisa são as que seguem: ADI 821, ADI 869, ADI 956, ADI 1755, ADI 2404, ADI 2815, ADI 3741, ADI 3742, ADI 3743, ADI 3758, ADI 3927, ADI 392, ADI 2398, ADI 3907, ADI 3944, ADI 4077, ADI 4741, ADI 4815, ADPF 130, ADPF 137 e ADO 22.

Para o presente trabalho, especificamente serão apresentadas as análises das seguintes ações já julgadas pelo STF e cuja temática está relacionada à propaganda eleitoral: ADI 956, ADI 3741, ADI 3742, ADI 3743, ADI 3758 e ADI 4741, conforme quadro abaixo.

Quadro 1-Ações no controle principal e abstrato de constitucionalidade pertinentes à temática das políticas públicas de comunicação e liberdade de expressão do pensamento localizadas em pesquisa empírica no site do Supremo Tribunal Federal e junto à Seção de Pesquisa de Jurisprudência e relacionadas à propaganda eleitoral

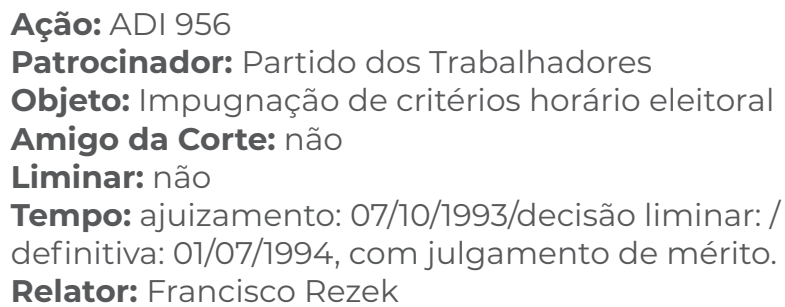

Patrocinador: Partido dos Trabalhadores

Objeto: Impugnação de critérios horário eleitoral Amigo da Corte: não

Liminar: não

Tempo: ajuizamento: 07/10/1993/decisão liminar: / definitiva: 01/07/1994, com julgamento de mérito. Relator: Francisco Rezek

Ação: ADI 3741

Patrocinador: Partido Social Cristão

Objeto: Impugnação da Lei Eleitoral

Amigo da Corte: não

Liminar: não

Tempo: ajuizamento: 31/05/2006/decisão liminar: / definitiva: 06/09/2006, com julgamento de mérito.

Relator: Ricardo Lewandowski 
Ação: ADI 3742

Patrocinador: Partido Democrático Trabalhista

Objeto: Impugnação da Lei Eleitoral

Amigo da Corte: não

Liminar: não

Tempo: ajuizamento: 08/06/2006/decisão liminar: / definitiva: 06/09/2006, com julgamento de mérito. Relator: Ricardo Lewandowski

Ação: ADI 3743

Patrocinador: Partido Trabalhista Cristão

Objeto: Impugnação da Lei Eleitoral

Amigo da Corte: não

Liminar: não

Tempo: ajuizamento: 08/06/2006/decisão liminar: / definitiva: 06/09/2006, com julgamento de mérito.

Relator: Ricardo Lewandowski

Ação: ADI 3758

Patrocinador: Ordem dos Músicos do Brasil

Objeto: Proibição de realização de showmício

Amigo da Corte: não

Liminar: não

Tempo: ajuizamento: 10/07/2006/decisão liminar: / definitiva:12/07/2006, sem julgamento de mérito.

Relator: Ricardo Lewandowski

Ação: ADI 4741

Patrocinador: Partido Popular Socialista - PPS

Objeto: Trata-se de Ação Direta de

Inconstitucionalidade proposta pelo Partido

Popular Socialista - PPS, a qual objetiva a

declaração de inconstitucionalidade parcial sem redução de texto dos arts. 36, caput e 57-B, inciso

IV, da Lei n 9.504/1997 (Lei das Eleições), a fim de

que se dê interpretação conforme a Constituição

aos dispositivos, "afastando-se qualquer intelecção que venha a impedir a livre manifestação de pensamento e de opinião através de redes sociais, inclusive o twitter, antes do dia 06 de julho dos anos eleitorais".

Amigo da Corte: não

Liminar: não

Tempo: ajuizamento: 20/03/2012 /decisão liminar: / definitiva: 26/02/2016, sem julgamento de mérito.

Relator: Roberto Barroso

Fonte: Elaborado pelo autor com base na pesquisa realizada no site do STF e junto à Seção de Pesquisa de Jurisprudência e com base nos incidentes processuais localizados em http:// www.stf.jus.br/portal/processo/pesquisarProcesso.asp

As demais ações, 15 no total, tratam de outros assuntos relacionados às políticas de comunicação, como, por exemplo, classificação indicativa e propaganda e publicidade comercial, temas que já foram ou serão abordados em outros trabalhos acadêmicos e artigos científicos.
Para a análise das ações, o método utilizado foi o indutivo, com o exame das ementas, acórdãos, relatórios e votos dos relatores proferidos em cada uma das 6 ações selecionadas. Esse recorte se justifica, pois considera-se, de acordo com Silva (2013, p. 568), que ementas e acórdãos expressam "the only two collective products of this decision -making process" (os únicos dois produtos coletivos do processo de decisão - tradução minha) do Supremo Tribunal Federal. ${ }^{8}$

Em relação aos relatórios e votos dos relatores, considera-se que a esses Ministros são atribuídas inúmeras funções decisórias, como por exemplo: ordenar e dirigir o processo, submeter questões de ordem ao plenário, determinar as medidas em caráter de urgência, com apreciação ad referendum do colegiado, pedir dia para julgamento dos processos quando já tiver proferido o seu voto. Ainda pode arquivar ou negar recurso intempestivo, incabível ou que contraria jurisprudência do tribunal, dentre outras funções.

Sobre o papel dos relatores no âmbito congressual, Souza (2003, p. 43) menciona que os ocupantes dessa função exercem um
papel importante nos processos decisó- rios na medida que influem sobrema- neira na elaboração dos anteprojetos encaminhados à votação. Como centrali- zadores de todas as informações disponí- veis no âmbito de sua atuação formal, os relatores dispõem de um amplo raio de intervenção no que se refere ao conteú- do mesmo das proposições contidas em seus pareceres.

Essa constatação pode ser feita também no âmbito judicial, onde o relator de um processo exerce uma função privilegiada em

\footnotetext{
8 No entanto, é importante frisar que não se desconsidera aqui e também não se desconhece que essa opção de análise não é imune de críticas e questionamentos quanto ao recorte efetuado. Alguns trabalhos contestam essa opção, tais como Silva (2016) e Costa (2014). Também não se desconsidera que o processo decisório do STF é caracterizado pelo julgamento em série, com apresentação dos votos dos Ministros em separado. Contudo, como dito por Silva (2013), ementa e acórdão são os documentos coletivos da corte.
} 
relação aos demais membros julgadores, concentrando em suas mãos grandes poderes, "[...] isso porque é ele quem escreve o relatório distribuído para os outros Ministros tomarem conhecimento do caso, sendo dele a primeira opinião a ser manifestada sobre o assunto." (OLIVEIRA, 2006, p. 87).

Para a análise dos julgados considerou-se: quem foi o propositor da ação; qual o pedido feito na ação, ou seja, qual a argumentação de confronto entre a lei questionada e o texto constitucional; a época em que foi questionada a constitucionalidade da lei e quando a ação foi julgada, no intuito de analisar o lapso temporal entre a entrada em vigor da lei, o seu questionamento junto ao Supremo e a efetiva decisão proferida por esse órgão; decisão consensual ou não, ou em outros termos, se a decisão foi tomada de forma unânime ou por maioria de votos; se a decisão foi por maioria, qual o Ministro que criou o impasse no julgamento e com qual argumento.

Na análise das ações, os argumentos dos Ministros serão reproduzidos em trechos e na íntegra e ao final da apresentação dos argumentos dos Ministros, serão traçadas breves considerações sobre o julgado.

A técnica de pesquisa proposta se aproxima ao que foi mencionado por Canotilho (2003) como método de trabalho briefing a case, pois foram contextualizados os casos, analisados os textos e os significados das normas, apresentadas as controvérsias constitucionais, os argumentos, a retórica argumentativa, e por fim, a decisão do caso pelo STF, tal como sugerido por Canotilho.

Trata-se, portanto, de "um exercício de Dogmática da Decisão, mediante análise crítica de algumas decisões recentes do Supremo Tribunal Federal" (RAMOS, 2015, p. 30).

\section{Apresentação dos julgados}

\subsection{ADI 956}

O Partido dos Trabalhadores ajuizou, em outubro de 1993, Ação Direta de Inconstitucionalidade, impugnando junto ao Supremo Tribunal Federal critérios legais impostos para o horário eleitoral pela Lei n 8.713/1993, que regulamentava as normas para as eleições de 1994, e que, em resumo, determinava que os programas a serem veiculados no horário eleitoral gratuito deveriam ser realizados em estúdio, podendo utilizar música ou jingle criados para a campanha, vedando-se a utilização de gravações externas, montagens ou trucagens. Sustentava o partido, na oportunidade, afronta ao princípio da liberdade de informação e de imprensa, previsto no artigo 220 da Constituição Federal. A ação foi julgada improcedente em juIho de 1994, por maioria dos votos, declarando-se a constitucionalidade dos dispositivos impugnados, vencidos os Ministros Marco Aurélio e Celso de Mello.

No relatório, Ministro Francisco Rezek relaciona a propaganda eleitoral gratuita com o artigo 220 da Constituição e estabelece uma distinção: enquanto esse último teria como destinatários os meios de comunicação, a propaganda eleitoral destina-se aos partidos políticos, únicos responsáveis pelo conteúdo da propaganda eleitoral.

No voto, o Ministro relator estabelece ainda uma distinção entre o horário eleitoral gratuito, financiado pelo Estado e o acesso gratuito ao rádio e televisão, garantido aos partidos políticos pelo artigo $17, \S 3^{\circ} \mathrm{da}$ Constituição, o direito de antena.

De acordo com o relator, o horário eleitoral gratuito não tem sede constitucional, diferentemente do direito de antena, e aquele 
tem o objetivo de "igualizar, por métodos ponderados, as oportunidades dos candidatos de maior e menor expressão econômica na sua oportunidade de expor ao eleitorado suas propostas" (BRASIL, 1993, p. 268).

Trata-se de fato de financiamento estatal de campanha e propaganda eleitoral, portanto, é legítimo estabelecer critérios legais que limitem o conteúdo, o que não seria permitido no caso do direito de antena. O relator, por não encontrar sede constitucional para a disciplina do horário eleitoral gratuito, entendeu que caberia ao legislador ordinário estabelecer as regras, julgando, diante disso, improcedente a ADI. O relator foi acompanhado em seu voto pelos Ministros IImar Galvão, Carlos Velloso, Sepúlveda Pertence, Neri da Silveira e Moreira Alves, vencidos os Ministros Marco Aurélio e Celso de Mello. Os Ministros Sydney Sanches e Paulo Brossard não participaram do julgamento.

No primeiro voto divergente, o Ministro Marco Aurélio aduz que o artigo impugnado da lei rechaça "a manifestação do pensamento e a criação preservadas mediante o disposto no artigo 220 da Constituição Federal", fato que impede "a possibilidade de um certo partido, um certo candidato, produzir programa que revele, até mesmo, a realidade nacional, os grandes contrastes no campo social que temos no Brasil, alfim, as desigualdades existentes", reconhecendo desta forma a inconstitucionalidade do artigo da lei eleitoral (BRASIL, 1993, p. 293).

Ministro Celso de Mello, também divergente do relator, trata a questão a partir do direito de antena, não diferenciando esse direito do horário eleitoral gratuito. De acordo com o Ministro, muito embora a Constituição estabeleça a necessidade de legislação infraconstitucional para o exercício desse direito, ela não conferiu ao legislador a possibilidade de "restringir os meios e ditar as técnicas de exercício dessa liberdade fundamental" (BRASIL, 1993, p. 296). Segundo o Ministro a ordem democrática é informada pelas liberdades de expressão do pensamento, sendo esses direitos representados pela possibilidade conferida a todos de se manifestarem "sem qualquer possibilidade de intervenção estatal na conformação legislativa dessa prerrogativa básica", ressaltando, à evidência, que abusos poderão ser solucionados a posteriori mediante sanções jurídicas, sendo inaceitável a imposição de restrições prévias (BRASIL, 1993, p. 297). Continua o voto afirmando "que o Estado não pode dispor de poder algum sobre a palavra, sobre as idéias e sobre os modos e técnicas de sua divulgação" e que a "liberdade de expressão do pensamento representa, em seu próprio e essencial significado, um dos fundamentos em que repousa a ordem democrática", reconhecendo, com esses fundamentos, a inconstitucionalidade do dispositivo questionado (BRASIL, 1993, p. 299).

\subsection{ADI $3741 / 3742 / 3743$}

Três partidos políticos - Partido Social Cristão (ADI 3741), Partido Democrático TrabaIhista (ADI 3742) e Partido Trabalhista Cristão (ADI 3743) - ajuizaram ações diretas de inconstitucionalidade, em maio de 2006, em relação à Lei n 11.300/2006, conhecida como "Mini-Reforma Eleitoral", que alterou dispositivos da Lei n 9.504/1997, que trata das normas para as eleições (Lei das Eleições), e que dispunha sobre propaganda, financiamento e prestação de contas das despesas com campanhas eleitorais.

O questionamento quanto à constitucionalidade da lei dizia respeito a não observância do princípio da anterioridade da lei 
eleitoral. As ADIs foram julgadas parcialmente procedentes, por decisão unânime, declarando-se tão somente a inconstitucionalidade da lei que vedava "a divulgação de pesquisas eleitorais por qualquer meio de comunicação, a partir do décimo quinto dia anterior até as 18 (dezoito) horas do dia do pleito" (BRASIL, 2006, n.p.). Estiveram ausentes do julgamento os Ministros Gilmar Mendes e Cezar Peluso.

O Ministro relator Ricardo Lewandowski, em seu voto, afasta a alegada inconstitucionalidade argumentada pelos partidos referente ao princípio da anterioridade, lastreando seu raciocínio em jurisprudência própria da Corte que ente que o princípio da anterioridade apenas protege o processo eleitoral em si, afirmando o $\mathrm{Mi}$ nistro que a lei questionada em nenhum momento altera regras do processo eleitoral. A lei apenas altera regras relacionadas à propaganda, financiamento e prestação de constas, regras meramente procedimentais.

Em relação ao artigo 35-A, declarado inconstitucional, confronta o relator esse dispositivo com a liberdade de informação, considerada "como corolário da liberdade de expressão" e "que constitui um valor indissociável da idéia de democracia no mundo contemporâneo" (BRASIL, 2006, n.p.). Fundamenta a inconstitucionalidade do artigo nos "princípios da razoabilidade e da proporcionalidade", indicando que medidas restritivas de direitos devem ser declaradas inconstitucionais quando contenham "limitações inadequadas, desnecessárias ou desproporcionais", concluindo que a restrição do artigo é inadequada, desnecessária e desproporcional (BRASIL, 2006, n.p.).

\subsection{ADI 3758}

A Ordem dos Músicos do Brasil ajuizou, em 10 julho de 2006, Ação Direta de Inconstitucionalidade em relação à proibição de realização de showmício determinada pela Lei $n^{\circ} 11.300 / 2006$, mencionada acima, que dispunha sobre propaganda, financiamento e prestação de contas em eleições, alegando afronta à livre expressão artística, prevista no artigo $5^{\circ}$, IX da Constituição Federal.

A ministra Ellen Gracie, em 12 de julho de 2006, negou seguimento à ação por ilegitimidade ativa do proponente. Não houve, portanto, enfrentamento de questões relacionadas à liberdade de expressão.

\subsection{ADI 4741}

Tratou-se de Ação Direta de Inconstitucionalidade proposta, em março de 2012, pelo Partido Popular Socialista - PPS, a qual objetiva a declaração de inconstitucionalidade parcial sem redução de texto dos artigos 36, caput e 57-B, inciso IV, da Lei n 9.504/1997 (Lei das Eleições), a fim de que se dê interpretação conforme a Constituição aos dispositivos, "afastando-se qualquer intelecção que venha a impedir a livre manifestação de pensamento e de opinião através de redes sociais, inclusive o twitter, antes do dia 06 de julho dos anos eleitorais" (BRASIL, 2012, n.p.).

De acordo com o Ministro relator Roberto Barroso (BRASIL, 2012, n.p.), o autor sustentava na ação

que a interpretação dada a esse conjunto normativo conduziria a uma indevida restrição do direito à manifestação do pensamento pela rede social Twitter, na medida em que se afirma que ela só poderá ocorrer após o dia 05 de julho dos anos eleitorais.

Solicita então o proponente que se dê in- 
terpretação conforme a Constituição para "afastar qualquer entendimento que impeça a livre manifestação do pensamento e da opinião nas redes sociais, inclusive no Twitter, antes de 05 de julho do ano das eleições" (BRASIL, 2012, n.p.).

O relator, em fevereiro de 2016, extinguiu o processo sem julgamento de mérito, reconhecendo "a perda do interesse de agir, tendo em vista a alteração do teor" do artigo 36, alterado pela Lei $n^{\circ} 13.165 / 2015$, que fora impugnado e que passou a determinar que "Não serão consideradas propaganda antecipada e poderão ter cobertura dos meios de comunicação social, inclusive via internet: I - a manifestação e o posicionamento pessoal sobre questões políticas nas redes sociais". (BRASIL, 2012, n.p.).

\section{Considerações sobre os julgamentos em sede de conclusão}

Das seis ações ajuizadas relacionadas à propaganda eleitoral, cinco delas foram patrocinadas por partidos políticos e uma por ordem profissional. O Supremo enfrentou o mérito da questão em quatro oportunidades, extinguindo o processo em duas ocasiões, uma por perda do objeto e outra por ilegitimidade ativa do proponente, no caso, a Ordem dos Músicos do Brasil.

Ao enfrentar o mérito das questões colocadas para julgamento, a Corte teve a oportunidade de tratar da liberdade de expressão do pensamento nas decisões.

Na primeira oportunidade (ADI 956), entendeu o tribunal, nos termos do voto do relator, que a propaganda eleitoral não tem sede constitucional, bem como diferencia-se do direito de antena, constitucionalmente garantido aos partidos políticos. Entendeu ainda que o regramento da propaganda eleitoral direciona-se aos partidos políticos, responsáveis pelo conteúdo da programação e não aos meios de comunicação.

Por esses motivos, acrescentando que a propaganda eleitoral é financiada pelo Estado, decidiu o tribunal pela possibilidade de restrições legais, tais como proibições de utilização de gravações externas, montagens ou trucagens - conforme o definido na lei impugnada pelo partido político patrocinador da ADI, - não sendo possível, no entendimento do Ministro Rezek, a imposição de restrições ao direito de antena, por ter esse sede constitucional.

Em voto divergente o Ministro Celso de Mello não diferencia direito de antena de propaganda eleitoral, e, de acordo com o voto, a Constituição não conferiu ao legislador ordinário a possibilidade de restrição à liberdade de expressão nas campanhas políticas. O Ministro conecta a liberdade de expressão à democracia, mencionando que - Estado não pode intervir, mesmo através de legislação, naquele direito fundamental, sendo certo que eventuais abusos podem ser solucionados judicialmente a posteriori.

Nas outras três ações (ADI 3741/3742/3743), nas quais houve o enfrentamento do mérito, a temática da liberdade de expressão foi fundamento para a declaração de inconstitucionalidade de dispositivo da lei eleitoral que vedava a divulgação de pesquisa eleitoral em período próximo do pleito. De acordo com o Ministro Lewandowski, a vedação da lei afrontava o direito à liberdade de informação, corolário da liberdade de expressão, sendo essa um valor indissociável da democracia, logo, a vedação é inconstitucional.

Observe-se que na fundamentação dos votos na ADI 956 os Ministros do Supremo 
trataram de duas coisas distintas, do direito de antena e da propaganda eleitoral, ou em outra terminologia, do Horário Gratuito de Propaganda Eleitoral (HGPE).

O primeiro, previsto no artigo $17, \S 3^{\circ}$ da Constituição, dispõe que "partidos políticos têm direito a recursos do fundo partidário e acesso gratuito ao rádio e televisão, na forma da lei". Enquanto a propaganda eleitoral, de fato, não tem sede constitucional, no entanto está regulada por lei ordinária que estabelece regras para as eleições, conforme determina o artigo 16 da Constituição, nos seguintes termos: "A lei que alterar o processo eleitoral entrará em vigor na data de sua publicação, não se aplicando à eleição que ocorra até um ano da data de sua vigência.".

Até novembro de 2017 esses direitos estavam regulados por leis ordinárias distintas. O direito de antena, pela Lei n 9.096/1995, denominada Lei dos Partidos Políticos, que tratava especificamente da propaganda política partidária, nos artigos 45 a 49, vedando-se expressamente a propaganda eleitoral de candidatos na exibição desses programas (art. $45, \S 1^{\circ}, \mathrm{II}$ ). Contudo, observese que a Lei $n^{\circ}$ 9.096/1995 foi alterada pela Lei $n^{\circ} 13.487 / 2017$, abolindo-se do sistema jurídico brasileiro, via legislação ordinária, o direito de antena dos partidos políticos para o exercício da propaganda partidária, sendo evidente a inconstitucionalidade dessa medida, pois a lei ordinária restringe um direito previsto constitucionalmente aos partidos políticos.

Por sua vez, a propaganda eleitoral gratuita continua sendo regulamentada pela Lei n 9.504/1997, com as alterações anuais posteriores, conforme determina o artigo 16 da Constituição, sendo a última delas as promovidas pela Lei $n^{\circ} 13.488 / 2017$. O regra- mento infraconstitucional da propaganda eleitoral gratuita está contido nos artigos 44 a 57-I da referida lei.

Essa distinção está em consonância com a Constituição e legislação portuguesa, fontes inspiradoras do direito de antena da Constituição Federal.

De acordo com Correia (2005, p. 536-537), a redação atual da Constituição da República Portuguesa, no artigo $40^{\circ}$, "consagra três modalidades de direito de antena", a saber:

\begin{abstract}
a) Direito de antena geral dos partidos políticos, das organizações sindicais, profissionais e representativas das actividades económicas (art. $40^{\circ}, \mathrm{n}^{\circ}{ }^{1}$ ); b) Direito de antena específico dos partidos da oposição parlamentar (art. $40^{\circ}$, n. $^{\circ} 2$ ); Direito de antena nos períodos eleitorais dos concorrentes (art. $40^{\circ}, \mathrm{n}^{\circ} 3$ ) ... As duas primeiras modalidades estão regulamentadas na Lei da Rádio e na Lei de Televisão e obrigam apenas as estações públicas de rádio e de televisão. A terceira está regulamentada nas leis eleitorais e obriga as estações de rádio e de televisão de âmbito nacional e regional, públicas e privadas.
\end{abstract}

Essa terceira modalidade - direito de antena em períodos eleitorais - está relacionada diretamente às "campanhas eleitorais" (CORREIA, 2005, p. 543).

Deste modo, é possível propor, de acordo com a legislação constitucional portuguesa, uma classificação do direito de antena no direito brasileiro da seguinte forma: direito de antena (em sentido lato) - direito de antena para propaganda política partidária e direito de antena para propaganda eleitoral.

No caso brasileiro, apenas o primeiro, conforme já mencionado, encontra guarida constitucional, sendo um direito de exclusividade dos partidos políticos, diferentemente do direito português que contempla também a possiblidade de fruição desse direito às organizações sindicais, profissionais e re- 
presentativas das atividades econômicas. No entanto, como já dito, a Lei n 13.487/2017 extinguiu esse direito dos partidos políticos, em flagrante inconstitucionalidade.

Seguindo essa orientação do direito português, há no Brasil propostas de regulação do direito de antena. Trata-se especificamente da proposta do Fórum Nacional pela Democratização da Comunicação (FNDC), que encabeça uma campanha para propor um projeto de lei de iniciativa popular para regulamentar a comunicação social eletrônica no Brasil. No anteprojeto há a proposta, contida no artigo 21, de que "as emissoras de televisão terrestre ou rádio ou redes consideradas como de poder de mercado significativo deverão ... assegurar, como direito de antena, 1 hora por semestre para cada um de 15 grupos sociais relevantes, definidos pelo órgão regulador por meio de edital com critérios transparentes e que estimulem a diversidade de manifestações."

Diante do que foi exposto, infere-se no presente trabalho e de acordo as decisões de mérito proferidas pela corte nas quatro ações analisadas e relacionadas à propaganda eleitoral não ser possível estabelecer um modus operandi do Supremo Tribunal Federal quando do julgamento dessas ações. Essa impossibilidade pode estar atrelada ao interregno de tempo entre as decisões, a primeira de 1994 e a outra de 2006, 12 anos depois.

Espera-se que no desenvolvimento da pesquisa possa-se indicar um modus operandi do Supremo do Tribunal Federal quando do julgamento de ações relacionadas às políticas de comunicação atreladas à liberdade de expressão do pensamento.

\section{Referências}

Aguillar, F. H. (2006). Direito econômico. São Paulo: Atlas.

Brasil (1993). Supremo Tribunal Federal. Ação direta de inconstitucionalidade n. 956, de 07 de novembro de 1993. Disponível em: <http://www.stf.jus.br/portal/ processo/pesquisarProcesso.asp>. Acesso em: janeiro/ fevereiro de 2017.

(2006a). Supremo Tribunal Federal. Ação direta de inconstitucionalidade n. 3741, de 31 de maio de 2006. Disponível em: <http://www.stf.jus.br/portal/ processo/pesquisarProcesso.asp>. Acesso em: janeiro/ fevereiro de 2017.

(2006b). Supremo Tribunal Federal. Ação direta de inconstitucionalidade n. 3742, de 08 de junho de 2006. Disponível em: <http://www.stf.jus.br/portal/ processo/pesquisarProcesso.asp>. Acesso em: janeiro/ fevereiro de 2017.

(2006c). Supremo Tribunal Federal. Ação direta de inconstitucionalidade n. 3743, de 08 de junho de 2006. Disponível em: <http://www.stf.jus.br/portal/ processo/pesquisarProcesso.asp>. Acesso em: janeiro/ fevereiro de 2017.

(2006d). Supremo Tribunal Federal. Ação direta de inconstitucionalidade n. 3758, de 10 de julho de 2006. Disponível em: <http://www.stf.jus.br/portal/ processo/pesquisarProcesso.asp>. Acesso em: janeiro/ fevereiro de 2017.

(2012) Supremo Tribunal Federal. Ação direta de inconstitucionalidade n. 4741, de 20 de março de 2012. Disponível em: <http://www.stf.jus.br/portal/processo/pesquisarProcesso.asp>. Acesso em: janeiro/fevereiro de 2017.

Brittos, V. C.; Nazário, P. M. (2011). Conselho Federal de Jornalismo: uma corporação necessária. Revista de Estudios para el Desarollo Social de la Comunicación, 06, 63-82.

Canotilho, J. J. G. (2003). Direito constitucional e teoria da constituição. 7 ed. Coimbra: Almedina.

Carvalho, V. M. de. (2002). Regulação de serviços públicos e intervenção estatal na economia. In Faria, J. E. (Org), Regulação, direito e democracia (pp. 13-26). São Paulo: Editora Fundação Perseu Abramo.

Correia, L. B. (2005). Direito da Comunicação Social. v. 1. Coimbra: Almedina.

Costa, T. M. da. (2014). Conteúdo e alcance da decisão do STF sobre a lei de imprensa na ADPF 130. Revista de Direito GV, 10(1), 119-154. 
Garapon, A. (2001). O juiz e a democracia: o guardião das promessas. 2. ed. Rio de Janeiro: Revan.

Gonçalves, M. E. (2003). Direito da informação: novos direitos e formas de regulação na sociedade da informação. Coimbra: Almedina.

Habermas, J. (2003). Direito e democracia: entre facticidade e validade. Rio de Janeiro: Tempo Brasileiro.

Koerner, A; Maciel, D. A. (2002). Sentidos da judicialização da política: Duas análises. Lua Nova, 57, 113-134.

Maus, I. (2000). Judiciário como superego da sociedade. O papel da atividade jurisprudencial na sociedade órfã. Novos Estudos Cebrap, 58, 183-202.

Mendes, C. H. (2011). Direitos fundamentais, separação de poderes e deliberação. São Paulo: Saraiva.

(2013). Constitutional courts and deliberative democracy. Oxford: Oxford University Press.

Nitrini, R. V. (2013). Liberdade de informação e proteção ao sigilo da fonte: desafios constitucionais na era da informação digital, Mestrado em Direito, USP, São Paulo.

Oliveira, F. L. (2006). Justiça, profissionalismo e política: O Supremo Tribunal Federal e o controle da constitucionalidade das leis no Brasil (1988-2003). Dou torado em Ciências Sociais - Centro de Educação e Ciências Humanas, Universidade Federal de São Carlos, São Carlos.

Ramos, E. da S. (2015). Ativismo judicial: parâmetros dogmáticos. 2 ed. São Paulo: Saraiva.

Reale Junior, M. (2010). Limites à liberdade de expressão. Espaço Jurídico, 11, 2, 374-401.

Sadek, M. T. (1995). A organização do poder judiciário no Brasil. In, Sadek, M. T. (Org.), Uma introdução ao estudo da justiça (pp. 9-16). São Paulo: Idesp/ed. Sumaré. Shapiro, M.; Sweet, A. S. (2002). On law, politics, and judicialization. Oxford: Oxford University Press.

Silva, V. A. da. (2009). O STF e o controle de constitucionalidade: deliberação, diálogo e razão pública. RDA, 250, 197-227.

(2010). Interpretação constitucional e sincretismo metodológico. In, Silva, V. A. da. (Org.), Interpretação constitucional (pp. 115-143). São Paulo: Malheiros. (2013). Deciding without deliberation. IJCL, 11, 3, 557-584.

(2016). O relator dá voz ao STF? Revista de Estudos Institucionais, 2, 2, 648-669.

Souza, M. T. (2003). O processo decisório na constituição de 1988: práticas institucionais. Lua Nova, 58, 37-60. Tate, C. N., Vallinder, T. (1994). The global expansion of judicial power. New York: New York University Press. Vianna, L. W; et al. (1999). A judicialização da política e das relações sociais no Brasil. Rio de Janeiro: Revan. Vieira, O. V. (2002). Supremo Tribunal Federal: jurisprudência política. 2. ed. São Paulo: Malheiros.

Zylbersztajn, J. (2008). Regulação de mídia e colisão entre direitos fundamentais. Mestrado em Direito, Universidade de São Paulo, São Paulo.

Data de submissão: 13/04/2017

Data de aceite: 25/06/2018 